Communication

\title{
Preliminary Results on Light Conditions Manipulation in Octopus vulgaris (Cuvier, 1797) Paralarval Rearing
}

\author{
Diego Garrido $^{1}$ (D) $^{\text {, Diana B. Reis }}{ }^{2,3}$, Diego Orol ${ }^{3}$, Rui A. Gonçalves ${ }^{2,4} \mathbb{C}^{\mathbb{D}}$, M. Virginia Martín ${ }^{1}$, \\ António V. Sykes ${ }^{2}$ (D) , Covadonga Rodríguez ${ }^{3}$, Beatriz C. Felipe ${ }^{1}$, Xiaodong Zheng ${ }^{5}$, \\ Luis Lagos ${ }^{6}$ and Eduardo Almansa ${ }^{1, *}$ \\ 1 Centro Oceanográfico de Canarias, IEO, Vía Espaldón, Dársena Pesquera, Parcela 8, \\ 38180 Santa Cruz de Tenerife, Spain; diegogarridolorenzo@gmail.com (D.G.); \\ virginia.martin@ieo.es (M.V.M.); beatriz.felipe@ieo.es (B.C.F.) \\ 2 CCMAR, Centro de Ciências do Mar, Universidade do Algarve, 8005-139 Faro, Portugal; \\ diana_b_reis@hotmail.com (D.B.R.); ralexandr3@gmail.com (R.A.G.); asykes@ualg.pt (A.V.S.) \\ 3 Universidad de La Laguna, Faculty of Sciences, Biology Section, 38206 San Cristóbal de La Laguna, Spain; \\ diego.orol@hotmail.com (D.O.); covarodr@ull.es (C.R.) \\ 4 BIOMIN Holding GmbH, Erber Campus 1, 3131 Getzersdorf, Austria \\ 5 Fisheries College, Ocean University of China, Qingdao 266003, China; xdzheng@ouc.edu.cn \\ 6 AZTI, Txatxarramendi Ugartea z/g, 48395 Sukarrieta (Bizkaia), Spain; luiselagosr@yahoo.es \\ * Correspondence: eduardo.almansa@ieo.es; Tel.: +34-922-549-400
}

Academic Editor: Maria Angeles Esteban

Received: 18 September 2017; Accepted: 20 November 2017; Published: 24 November 2017

\begin{abstract}
High paralarvae mortality is a major bottleneck currently hindering the control over the lifecycle of common octopus (Octopus vulgaris Cuvier, 1797). It is believed that this problem might be related to either zoo-technical and/or nutritional aspects. The present paper is focused on the study of different zoo-technical aspects related to light conditions on the rearing of paralarvae, including the effects of polarization in prey ingestion, the use of a blue filter to simulate natural conditions, and the use of focused light to avoid reflections of the rearing tank's walls. In the first experiment, O. vulgaris paralarvae ingestion of Artemia sp. and copepods (Tisbe sp.) was assessed under either normal or polarized light. In the second experiment, the effect of a blue filter with natural light or focused artificial light on growth and mortality was assessed over 15 days of rearing. Ingestion rate was not influenced by light polarization. Nonetheless, a significantly higher ingestion of Artemia sp. with respect to copepods was observed. The blue filter promoted the use of natural light conditions in Octopus paralarval culture, while focused light reduced the collision of the paralarvae against the walls. However, no significant differences were found in paralarval growth nor survival.
\end{abstract}

Keywords: blue filter; Octopus vulgaris; paralarvae rearing; polarized light; reflection light

\section{Introduction}

The common octopus (Octopus vulgaris Cuvier, 1797) is an excellent candidate for aquaculture diversification, due to its easy adaptability to captivity conditions, high growth and reproduction rate, high economic value, high market demand, and dramatic natural stock capture decline [1]. However, high paralarvae mortality remains a bottleneck hindering the control over its lifecycle. This lack of control might be due to either zoo-technical or nutritional aspects [2]. In fact, not only providing preys with suitable nutritional value is important for paralarvae, but also the rearing setup must assure that preys are easily detected, to avoid an excess of energy expenditure in prey capture. In this sense, 
adaptation of aquaculture seawater systems design is important to reach proper growth, survival, and industrial-scale production.

Previous studies have shown that light and the surrounding environment are some of the major factors influencing survival, growth, and prey capture in cephalopods culture [3-6]. The use of artificial light, commonly used in the first life stage of finfish or cephalopod culture, differs in many aspects from the natural light found in the wild by paralarvae. It is known that light polarization and wavelength absorption, which vary according to depth and water physicochemical conditions, may affect cephalopods [7-10]. In the ocean, the natural light is mainly scattered by water molecules, turning the sunlight into polarized light. According to Shashar et al. [7,11], many marine organisms are able to recognize this type of light, using it for displacement, prey search (facilitating the detection of preys with high level of transparency), and communication (since some objects and animals are able to produce their own pattern of polarization). In fact, several studies have shown that the adult octopus is sensitive to polarized light $[12,13]$. Although octopus paralarvae maybe also sensitive, no studies have ever been performed to actually determine their sensitivity to polarized light or its effect in prey capture [14].

Villanueva et al. [15] showed that different preys induce different types of behavior in paralarvae. Artemia sp. is the most commonly used prey in O. vulgaris paralarvae rearing due to its availability and production logistics. Nonetheless, its nutritional value is not appropriate for paralarvae development and thus survival is low $[14,16]$. Copepods could be used as a possible alternative prey to feed paralarvae, due to its nutritional profile [17]. In fact, copepods are a natural prey of paralarvae [18-21] and a previous study using co-feeding of copepods (Acartia tonsa Dana, 1849) and Artemia sp. nauplii attained improved survival [16]. In addition, the use of copepods could also be advantageous due to its erratic swimming behavior, which could be attractive to octopus paralarvae [22]. Similar behavior has been found for crustacean zoeae, the main natural prey of O. vulgaris paralarvae $[16,23]$.

In the wild, differences in the light spectrum are depth dependent, since irradiance levels decrease with depth increase. Wavelengths are absorbed at different levels, with the pale blue-green rank $(\lambda \approx 450 \mathrm{~nm})$ being the one that reaches the greatest depth in oceanic waters [8]. According to Mangold [24], Otero et al. [25], and Roura et al. [26], O. vulgaris paralarvae are distributed in the water column from a depth of 20 to $100 \mathrm{~m}$. In this sense, specific light filters, which differently absorb the distinct spectrum ranks, could be used to simulate those irradiance conditions in captive environments such as culture tanks [27].

Previous trials, performed at the Spanish Institute of Oceanography (IEO) facilities, showed that paralarvae were attracted by the rearing tank walls with the most intense light reflection, promoting a paralarvae gathering near tank walls and increasing the number of collisions against it. However, when light reflection was eliminated, paralarvae moved away from the walls [28]. Those impacts may provoke skin lesions on mantle and tentacles, as described by Vidal et al. [29,30], which affects the development and survival of paralarvae. According to Villanueva and Norman [14], octopus paralarvae seem to display a positive photo tactic behavior. In fact, the use of light conditions to improve cephalopod rearing is not new. Sykes et al. [5] obtained increased growth and survival in cuttlefish hatchlings with the use of black tanks, which promoted a lower light intensity condition due to lower light reflections within the rearing tank. This study led those authors to test the use of different light intensities in black tanks, with the best results being achieved at low light intensities [31]. Both factors contributed to the weaning of Sepia officinalis from the first day after hatching on frozen food [32]. Therefore, tank light conditions could be an important factor in the rearing of visual animals including cephalopods.

In the present study, several light characteristics resembling those of natural environmental conditions were simulated in the rearing of $O$. vulgaris paralarvae. In the first trial, the effect of polarized light on paralarvae prey ingestion (fed either Artemia sp. or Tisbe sp.) was analyzed. In the second, a specific filter with natural light was tested to achieve a light spectrum similar to $20-40 \mathrm{~m}$ of 
ocean depth (natural depth of wild individuals), and artificial light reflection on rearing tanks was avoided, studying their effects on paralarvae growth and survival after 15 days of rearing.

\section{Results and Discussion}

The results of polarized light effect (Experiment 1; Trials 1 and 2) on new octopus hatchling ingestion are shown in Table 1. No significant differences were detected in prey ingestion either in Artemia sp. or copepods regarding polarization. The ability of cephalopods to use polarized light in the detection of transparent preys was previously reported by Shashar et al. [11], since the polarization of light can turn the preys visible to cephalopods, revealing their presence. Therefore, modifications in light polarization can change paralarvae prey choice [33]. The lack of differences observed in the present study suggests that, under our culture conditions, Artemia sp. and copepods seem to be easily located by the paralarvae regardless of light conditions (polarized or unpolarized).

Table 1. Number of preys (Artemia sp. or Tisbe sp.) ingested per day by Octopus vulgaris paralarvae under different light conditions (polarized (P) and unpolarized (UP) light).

\begin{tabular}{|c|c|c|c|c|c|c|c|c|c|c|}
\hline \multirow[b]{2}{*}{ Light } & \multicolumn{2}{|c|}{ Artemia sp. } & \multicolumn{2}{|c|}{ Tisbe sp. } & \multicolumn{3}{|c|}{ (Two-Way ANOVA) } & \multicolumn{3}{|c|}{ F Values and Degrees Freedom } \\
\hline & $\mathrm{P}$ & UP & $\mathrm{P}$ & UP & Light & Prey & Interaction & Light & Prey & Interaction \\
\hline Trial 1 & $35.3 \pm 2.3$ & $32.0 \pm 2.0$ & $20.7 \pm 4.2$ & $19.0 \pm 3.0$ & - & * & - & $\begin{array}{l}\text { F: } 2.1 ; \\
\text { d.f. } 1\end{array}$ & $\begin{array}{c}\text { F: } 64.4 ; \\
\text { d.f. } 1\end{array}$ & $\begin{array}{l}\text { F: } 0.2 ; \\
\text { d.f. } 1\end{array}$ \\
\hline Trial 2 & $30.0 \pm 2.0$ & $27.3 \pm 8.1$ & $10.7 \pm 2.3$ & $11.3 \pm 2.3$ & - & * & - & $\begin{array}{l}\text { F: } 0.6 ; \\
\text { d.f. } 1\end{array}$ & $\begin{array}{l}\text { F: } 43.6 ; \\
\text { d.f. } 1\end{array}$ & $\begin{array}{l}\text { F: } 0.3 ; \\
\text { d.f. } 1\end{array}$ \\
\hline
\end{tabular}

Data presented as means \pm SD (standard deviation); $N=3$; Abbreviations: F, F values and d.f., degrees freedom. * indicate significant differences in the studied variables $(p<0.01)$.

With respect to the type of prey, significant differences were found, with Artemia sp. nauplii being the most ingested prey $(p<0.01)$. The lower ingestion of copepods could be explained by several causes. The genus Tisbe is a benthic copepod [34,35] while paralarvae are mostly planktonic; this could have limited paralarvae predation and ingestion. On the other hand, paralarvae are known to be very selective in prey selection and capture, using a complex system of receptors, namely photoreceptors, mechanoreceptors, and chemoreceptors $[14,23]$. Therefore, additional studies with other preys and different rearing environments are necessary to better understand the effect of polarized light in the O. vulgaris paralarvae behavior.

The Artemia sp. ingestion in this study (27.3-35.3 Artemia nauplii/day) was higher than that registered by Márquez et al. [4] (0.8-16 Artemia metanauplii/day). The differences between both studies could be explained by several factors, namely the larger volume used in the present study (50 mL vs. $9.2 \mathrm{~mL})$, the lower light intensity $\left(100 \mathrm{lux}\left(0.15 \mathrm{~W} / \mathrm{m}^{2}\right)\right.$ vs. $\left.750 \mathrm{lux}\left(7.5 \mathrm{~W} / \mathrm{m}^{2}\right)\right)$, the lower prey density (1 nauplii/mL vs. 9.4 metanauplii/mL), prey size (nauplii vs. metanauplii), or the higher temperature $\left(22.6{ }^{\circ} \mathrm{C}\right.$ vs. $\left.20^{\circ} \mathrm{C}\right)$. Regarding the latter, high temperatures are associated to higher oxygen consumption and energy loss in paralarvae, increasing its prey consumption as it has been suggested by Repolho et al. [36]. On the other hand, Márquez et al. [4] suggested a saturating effect of prey density on paralarval prey intake, and Iglesias et al. [37] pointed out that O. vulgaris paralarvae showed higher prey attack at lower prey densities, as well as a preference for large Artemia sp. Finally, light intensity must be taken into account as an important factor in paralarval predation. Unfortunately, there are multiple parameters that can affect paralarvae behavior, therefore more studies should be performed in order to optimize O. vulgaris paralarvae rearing in a similar way to what has been done for other cephalopod species [38].

In Experiment 2, the effect of different light conditions in growth and survival of 15-day-old paralarvae was assayed. No differences were detected among treatments for 15-day-old paralarvae (Table 2). The blue filter treatment (resembling natural light conditions) displayed similar survival and growth values to those obtained with artificial light (control). Natural light in the culture of cephalopod paralarvae seems to have a negative effect on survival and could even cause stress on paralarvae due to instability in the photo-environment $[3,39]$. Therefore, the blue filter might reduce 
the abovementioned negative effects. However, it should be considered that the effect of natural light without the blue filter was not tested in the current study, and further studies are needed to clarify the potential benefits of this filter.

Table 2. Effect of different light conditions in O. vulgaris paralarvae growth and survival.

\begin{tabular}{cccc}
\hline & Control & Blue Filter & Focused Light \\
\hline VML (mm) & $1.63 \pm 0.11$ & $1.58 \pm 0.07$ & $1.70 \pm 0.07$ \\
SGR VML (\%/day) & $0.74 \pm 0.49$ & $0.50 \pm 0.33$ & $1.01 \pm 0.28$ \\
DML (mm) & $2.17 \pm 0.13$ & $2.10 \pm 0.12$ & $2.23 \pm 0.12$ \\
SGR DML (\%/day) & $0.89 \pm 0.45$ & $0.68 \pm 0.41$ & $1.09 \pm 0.38$ \\
Dry weight (mg) & $0.45 \pm 0.08$ & $0.41 \pm 0.10$ & $0.56 \pm 0.15$ \\
SGR weight (\%/day) & $4.92 \pm 1.42$ & $4.29 \pm 1.74$ & $6.44 \pm 1.84$ \\
Survival rate (\%) & $66.6 \pm 11.7$ & $60.4 \pm 9.0$ & $56.1 \pm 11.4$ \\
\hline
\end{tabular}

Data presented as means \pm SD; $N=6$; Abbreviations: VML, ventral mantel length, DML, dorsal mantle length and SGR, specific growth rate.

Regarding the focused light, paralarvae remained far from the tank walls since there were no light reflections on the tank walls, while in the control group, paralarvae contacted with tank walls, as a consequence of paralarvae positive photo tactics [14]. However, these observations were not recorded, and consequently could not be quantified. No skin lesions were detected in the control group (Figure 1), in spite of the abovementioned behavior. This could be explained by the low flow speed setup, since skin damage has been described to be associated with the use of strong hydrodynamics in paralarvae of Loligo opalescens [29] and O. vulgaris [16].

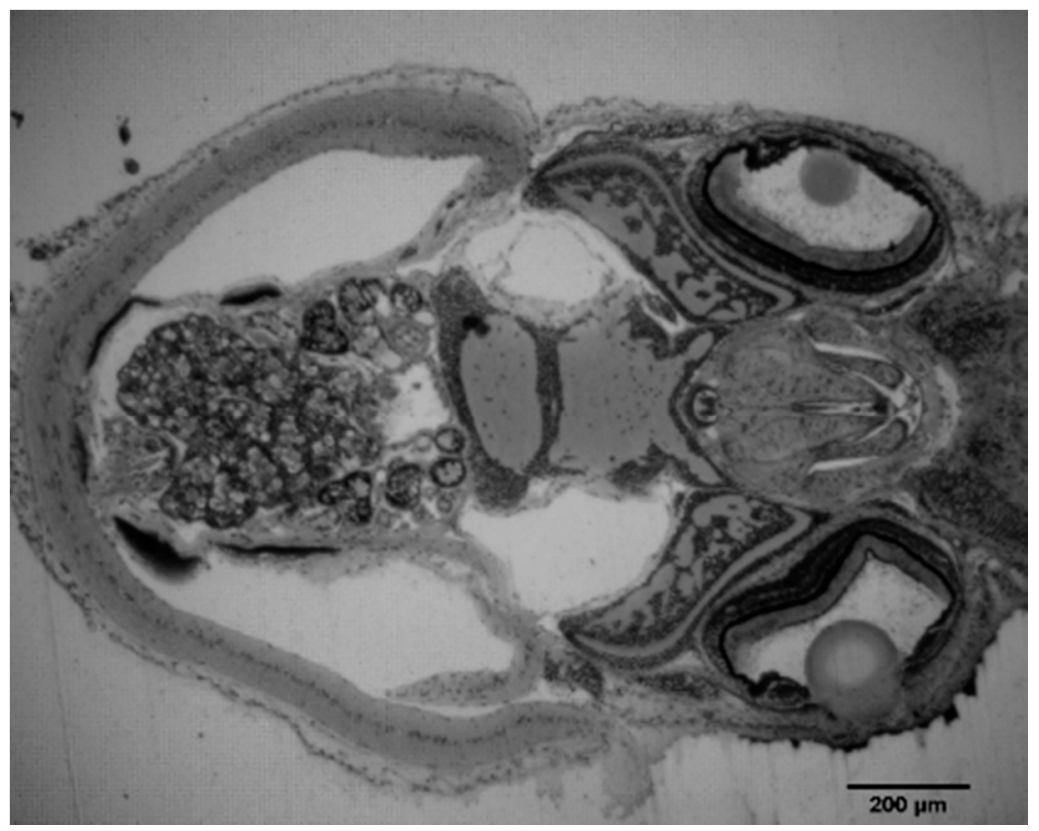

Figure 1. Dorsal histological cut of $O$. vulgaris paralarvae (control treatment) 15 days after hatching.

\section{Materials and Methods}

\subsection{Ethical Statement}

The experiments of this study were carried out before Directive 2010/63/EU came into force as national legislation in RD 53/2013 Spanish law. Nonetheless, all the procedures performed on live O. vulgaris in the present study were only applied by demonstrated competent users. 


\subsection{Octopus vulgaris Broodstock}

The O. vulgaris broodstock individuals were caught by professional artisanal fishermen in the coast of Tenerife (Canary Islands, Spain). Individuals $(N=10)$ with a mean wet weight (MWW) of $1309 \pm 503 \mathrm{~g}$, were then kept in 1000-L circular fiberglass tanks of a flow-through seawater system with a $5 \mathrm{~L} / \mathrm{min}$ inflow, under natural photoperiod (from 10L:14D to 11L:13D $\mathrm{h}$ of light (L) and dark (D)), with a water temperature of $18.90 \pm 0.64{ }^{\circ} \mathrm{C}$ and $36.8 \pm 0.14$ practical salinity unit (PSU) of salinity. Temperature was measured with a Tinytag Plus 2 (TGP-4020; Gemini Data Loggers Ltd., Chichester, West Sussex, UK) and salinity with a hand refractometer (ATAGO S/Mill-E, Tokyo, Japan).

Three octopuses with similar weight were placed in each tank, with a sex ratio of two females per male $\left(2 \circ: 1 \sigma^{7}\right)$. Adult octopuses were fed ad libitum with frozen squid (L. opalescencs) and frozen shrimp (Penaeus vannamei). The presence of eggs was daily verified and when an egg mass was observed inside the pot, the female was individualized in a tank with similar volume.

\subsection{Experiment 1-Effect of Polarized Light on Prey Capture}

For this experiment, two 50-L rectangular tanks, with a small opening on the top were subjected to polarized (P) or unpolarized (UP) light, which was attained with a specific lens (Washin Korea S.A., Cheoncheon-dong, South Korea). In each tank, a $100 \mathrm{~W}$ incandescent bulb was connected to a potentiometer to achieve an intensity of $100 \operatorname{lux}\left(0.15 \mathrm{~W} / \mathrm{m}^{2}\right.$, according to the factor $1 \mathrm{~W} / \mathrm{m}^{2}=683 \mathrm{lux}$, assuming wavelength at $555 \mathrm{~nm}$ [40]) at the water surface of the tank, which was measured with a LUTRON LX-101 luxmeter (Lutron Electronics Co, Coopersburg, PA, USA).

Six 50-mL glass beakers were placed inside each 50-L tank with different light (P and UP). Fifty preys were added to each beaker, either Artemia sp. nauplii (SepART; EG, INVE AQUACULTURE, Dendermonde, Belgium) or copepod (Tisbe sp.), collected from Brachionus plicatilis culture tanks at IEO own facilities. One newly hatched octopus was added to each beaker. Therefore, triplicates of prey were assessed under each type of light. After $24 \mathrm{~h}$, the number of prey ingested by each paralarvae was determined. To increase the statistical power of results, the experiment was performed twice. Average water temperature was $22.6 \pm 0.3^{\circ} \mathrm{C}$, and salinity was $36.8 \pm 0.14$ PSU.

\subsection{Experiment 2-Effect of Blue Filter or the Elimination of Light Wall Reflection on the Rearing of O. vulgaris Paralarvae}

Paralarvae rearing was performed during the first 15 days in 100-L fiberglass (black wall and white bottom) cylinder-conical tanks of a flow-through seawater system with a $1 \mathrm{~mL} / \mathrm{s}$ flow rate ( $85 \%$ water renovation/day). A total of 5400 paralarvae were used, at a density of 3 paralarvae/L (300 paralarvae/tank). Paralarvae were daily fed with 0.05-0.1 Artemia sp. metanauplii/mL (SepART; EG, INVE AQUACULTURE). Metanauplii were previously enriched over $24 \mathrm{~h}$ with $1 \times 10^{7} \mathrm{cells} / \mathrm{mL}$ of lyophilized Nannochloropsis gaditana (Ng; Fictoplancton Marino S.L. Cádiz, Spain) at a density of 2.4 nauplii $/ \mathrm{mL}$. Water temperature and dissolved oxygen saturation of the rearing tanks were daily measured with a METER PRO ODO oxymeter (YSI Inc., Yellow Springs, OH, USA), and were maintained at $20.1 \pm 0.26{ }^{\circ} \mathrm{C}$ and $101.5 \pm 1.8 \%$ of oxygen saturation, respectively. Every week, nitrogenous compounds and $\mathrm{pH}$ were measured with TETRAtest $\mathrm{NH}_{3}$ and $\mathrm{NO}_{2}$ aquarium kits (Tetra GmbH, Melle, Germany) and with a Hanna-HI-98107 pH Meter (Hanna Instruments, Ann Arbor, MI, USA). The values of $\mathrm{NH}_{3}$ and $\mathrm{NO}_{2}$ were $0-0.25 \mathrm{ppm}$ and $<0.3 \mathrm{ppm}$, respectively, while $\mathrm{pH}$ was $8.0 \pm 0.1$. Three different treatments with different light conditions and six replicates each were established: (I) Control (spread artificial light with no filter), (II) Blue filter (spread natural light with a filter that has a higher percentage of transmission ( $\geq 80 \%$ ) between 420 to $520 \mathrm{~nm}$ and a lower percentage (35\% to 70\%) between 520 to $700 \mathrm{~nm}$ ), and (III) focused light (focused artificial light with no filter) conditions. The different treatments shared a similar photoperiod of 12L:12D. Incident light was measured by pointing the sensor up towards the light source, while reflective light was measured by pointing the sensor down towards the tank [31]. In addition, to avoid abrupt changes in artificial light 
intensity, the light was switched on at 50\% intensity at 8:30 a.m. and only increased to $100 \%$ intensity after $30 \mathrm{~min}$.

The replicates of the control group had no disturbance on the normal rearing lighting conditions. The focused light group shared similar conditions of incident light intensity of 150-200 lux $\left(0.22-0.29 \mathrm{~W} / \mathrm{m}^{2}\right)$ at the air-water interface of the tank by using a $40 \mathrm{~W}$ incandescent bulb. To eliminate the light reflection of rearing tanks walls, a polyvinyl chloride (PVC) tube with a diameter of $160 \mathrm{~m}$ and a length of $250 \mathrm{~mm}$ was positioned around the light bulb so that light was focused at the tank bottom and no direct light reached the walls. On the other hand, in the blue filter group, replicate tanks were subjected to a natural light source with a specific blue filter, which mimicked irradiance conditions at 20-40 m ocean depth (DC Servicios Ambientales, Santa Cruz de Tenerife, Spain). In this group, a mean incident light intensity of $241 \pm 27 \mathrm{lux}\left(0.35 \pm 0.04 \mathrm{~W} / \mathrm{m}^{2}\right)$ over the filter was achieved with natural sunlight, which ranged from $90 \operatorname{lux}\left(0.13 \mathrm{~W} / \mathrm{m}^{2}\right)$ at 8:00 a.m. to $2000 \operatorname{lux}\left(2.93 \mathrm{~W} / \mathrm{m}^{2}\right)$ at 2:00 p.m., in our rearing facilities.

\subsection{Growth and Survival}

The growth of octopus paralarvae in Experiment 2 was determined by size and weight increment after 15 days of culture. Samples of 18 octopus hatchlings were collected at the beginning and at the end of the experiment from each trial treatment (three paralarvae per rearing tank). Hatchlings and 15-day-old paralarvae were anesthetized with $2 \%$ ethanol and measured in a magnifying glass (Nikon SMZ-10A-5x magnification, Nikon Corporation, Tokio, Japan) for the determination of ventral mantle length (VML) and dorsal mantle length (DML). These same individuals were euthanized in chilled seawater, washed in distilled water, oven-dried at $100^{\circ} \mathrm{C}$ for $20 \mathrm{~h}$, and then dry weighed in a Mettler AT201 precision scale (Mettler-Toledo S.A.E, L' Hospitalet de Llobregat, Spain). The data collected were used to calculate the specific growth rate for size and dry weight, SGR (\% dry weight or size $\times$ day $\left.^{-1}\right)=\left(\operatorname{Ln} W_{2}-\operatorname{Ln} W_{1}\right) / t \times 100$, where $W_{2}$ and $W_{1}$ are the final and the initial dry weight or size, respectively, $\mathrm{Ln}$ is the natural logarithm, and $t$ is the number of days of the experiment; and survival rate, $S(\%)=\left(N_{f} / N_{i}\right) \times 100$, where $N_{f}$ and $N_{i}$ are the final and initial number of octopus paralarvae in the rearing tank, respectively.

\subsection{Histology}

Since the objective of using a polarized filter was to enhance prey capture by paralarvae (Experiment 1), histological cuts were only performed in octopus paralarvae of control and focused light rearing treatments to determine possible differences in the amount of skin lesions (Experiment 2). Samples of 10 paralarvae, from three randomly selected rearing tanks of each group, were collected and fixed in formaldehyde at 20:1 (volume by sample). Afterwards, these were dehydrated in ethanol (70\%, $90 \%$, and $95 \%$ ). Pre-infiltration, infiltration, and polymerization was performed with the contents of a Heraeus Technovit 7100 kit (Heraeus Kulzer GmbH, Hanau, Germany). Longitudinal and transverse sections of $3 \mu \mathrm{m}$ were cut in a Microm HM 340 E microtome (Microm International GmbH, Walldorf, Germany) and stained with toluidine blue O, or Ehrlich's hematoxylin solution and eosin Y, or periodic acid-Schiff (PAS) solution. Staining solutions were acquired from Carl Roth GmbH + Co. KG (Karlsruhe, Germany).

\subsection{Data Analysis}

Results are presented as means \pm standard deviation (SD). Data were checked for normal distribution with the one-sample Shapiro-Wilk test [41] as well as for homogeneity of the variances with the Levene test [41] and, when necessary, arcsine transformation was performed [42]. The effect of light (polarized vs. unpolarized) and type of prey (Artemia vs. copepod) in paralarvae ingestion was assessed by two-way ANOVA [41]. When normality and/or homoscedasticity assumptions were not achieved, data were subjected to a non-parametric two-way ANOVA test based on rank transformation [41]. Growth rates were assessed by one-way ANOVA followed by a Tukey's post 
hoc test [41]. When normal distribution was not achieved, data were subjected to Kruskall-Wallis non-parametric test, followed by a Games-Howell non-parametric multiple comparison test [41]. Statistical analysis was performed using the SPSS package version 15.0 (SPSS Inc, Chicago, IL, USA).

\section{Conclusions}

In summary, polarized light did not have a significant influence on the predation rate of $O$. vulgaris paralarvae on different types of prey. Nonetheless, a significantly higher ingestion was observed in Artemia sp. respect to the copepod species under assessment. The blue filter promoted the use of natural light conditions in Octopus paralarval culture, while the focused light reduced the collision of paralarvae against the tank walls. However, no significant differences were found in paralarval growth or survival. Further studies should be performed in order to clarify and better understand the possible effects of light condition (light intensity, polarization, etc.) in the rearing of O. vulgaris paralarvae.

Acknowledgments: This work was partially supported by the research projects SEPIAMETA (PTDC/MAR/102348/2008) funded by Fundação para a Ciência e Tecnologia (FCT) and NUTRIPULPO, funded by JACUMAR 2010 (Spanish Government). Diego Garrido wish to thank the Instituto Español de Oceanografía for the grant FPI 2011 "Biomarcadores de estrés y metabolismo lipídico en las primeras fases de vida del pulpo común (Octopus vulgaris)" (BOE of November 3rd 2011). António V. Sykes (SFRH/BPD/36100/2007; Investigador FCT contract IF/00576/2014) and Diana B. Reis (SFRH/BD/76863/2011) wish to thank FCT for funding their grants and contracts. Covadonga Rodríguez belongs to the Instituto de Biomedicina de Canarias.

Author Contributions: E.A., C.R., M.V.M, and X.Z. were responsible for the design and supervision of the study. D.O., B.C.F., X.Z., and D.B.R. carried out the setup of the experiment, and were responsible for the maintenance of the animals as well as data collection. R.A.G. and A.V.S. performed the histology. D.G., L.L., and R.A.G. carried out data analysis. All authors contributed to interpretation of results and made major contributions to the manuscript. D.G. drafted the manuscript. All authors have read, revised, and approved the final version of the manuscript.

Conflicts of Interest: The authors declare no conflict of interest. The founding sponsors had no role in the design of the study; in the collection, analyses, or interpretation of data; in the writing of the manuscript, and in the decision to publish the results.

\section{References}

1. Vaz-Pires, P.; Seixas, P.; Barbosa, A. Aquaculture potential of the common octopus (Octopus vulgaris Cuvier 1797): A review. Aquaculture 2004, 238, 221-238. [CrossRef]

2. Iglesias, J.; Fuentes, L. Octopus vulgaris. Paralarval Culture. In Cephalopod Culture; Iglesias, J., Fuentes, L., Villanueva, R., Eds.; Springer: Dordrecht, The Netherlands, 2014; pp. 427-450.

3. Okumura, S.; Kurihara, A.; Iwamoto, A.; Takeuchi, T. Improved survival and growth in Octopus vulgaris paralarvae by feeding large type Artemia and Pacific sandeel, Ammodytes personatus: Improved survival and growth of common octopus paralarvae. Aquaculture 2005, 244, 147-157. [CrossRef]

4. Márquez, L.; Quintana, D.; Almansa, E.; Navas, J.I. Effects of visual conditions and prey density on feeding kinetics of paralarvae of Octopus vulgaris from a laboratory spawning. J. Molluscan Stud. 2007, 73, 117-121. [CrossRef]

5. Sykes, A.V.; Domingues, P.M.; Márquez, L.; Andrade, J.P. The effects of tank colours on the growth and survival of cuttlefish (Sepia officinalis, Linnaeus 1758) hatchlings and juveniles. Aquac. Res. 2011, 42, 441-449. [CrossRef]

6. Fernández-López, A.; Roo, F.J.; Socorro, J.; Hernández-Cruz, M.C.; Férnandez-Palacios, H.; Izquierdo, M.S. Crecimiento y Supervivencia de Paralarvas de Octopus vulgaris Cultivadas bajo Diferentes Intensidades de Luz. In Proceedings of the X Congreso Nacional de Acuicultura, Valencia, Spain, 17-21 October 2005; Sociedad Española de Acuicultura: Valencia, Spain, 2005; pp. 374-375.

7. Shashar, N.; Sabbah, S.; Cronin, T.W. Transmission of linearly polarized light in seawater: Implications for polarization signaling. J. Exp. Biol. 2004, 207, 3619-3628. [CrossRef] [PubMed]

8. Wozniak, B.; Dera, J. Introduction: Absorption of Sunlight in the Ocean. In Light Absorption in Sea Water; Laurence, A.M., Kevin, H., Eds.; Springer: New York, NY, USA, 2007; Volume 33, pp. 1-10.

9. Marshall, J.; Cronin, T. Polarization visión. Curr. Biol. 2011, 21, R101-R105. [CrossRef] [PubMed] 
10. Cartron, L.; Josef, N.; Lerner, A.; Mc Cusker, S.D.; Darmaillacq, A.-S.; Dickel, L.; Shashar, N. Polarization vision can improve object detection in turbid waters by cuttlefish. J. Exp. Mar. Biol. Ecol. 2013, 447, 80-85. [CrossRef]

11. Shashar, N.; Hanlon, R.T.; Petz, A.D.M. Polarization vision helps detect transparent prey. Nature 1998, 393, 222-223. [CrossRef]

12. Moody, M.F.; Parriss, J.R. The discrimination of polarized light by Octopus: A behavioural and morphological study. Zeitschrift Für Vergleichende Physiologie 1961, 44, 268-291. [CrossRef]

13. Shashar, N.; Cronin, T.W. Polarization contrast vision in Octopus. J. Exp. Biol. 1996, 199, 999-1004. [PubMed]

14. Villanueva, R.; Norman, M.D. Biology of the planktonic stages of benthic octopuses. Oceanogr. Mar. Biol. Annu. Rev. 2008, 46, 105-202.

15. Villanueva, R.; Nozais, C.; von Boletzky, S. Swimming behaviour and food searching in planktonic Octopus vulgaris Cuvier from hatching to settlement. J. Exp. Mar. Biol. Ecol. 1997, 208, 169-184. [CrossRef]

16. Iglesias, J.; Sánchez, F.J.; Bersano, J.G.F.; Carrasco, J.F.; Dhont, J.; Fuentes, L.; Linares, F.; Muñoz, J.L.; Okumura, S.; Roo, J.; et al. Rearing of Octopus vulgaris paralarvae: Present status, bottlenecks and trends. Aquaculture 2007, 266, 1-15. [CrossRef]

17. Lavens, P.; Sorgeloos, P. Manual on the Production and Use of Live Food for Aquaculture; Food and Agriculture Organization of the United Nations: Rome, Italy, 1996; Volume 361, p. 295.

18. Olmos-Pérez, L.; Roura, Á.; Pierce, G.J.; Boyer, S.; González, Á.F. Diet composition and variability of wild Octopus vulgaris and Alloteuthis media (Cephalopoda) paralarvae: A metagenomic approach. Front. Physiol. 2017, 8, 321. [CrossRef] [PubMed]

19. Roura, Á.; González, Á.F.; Pascual, S.; Guerra, Á. A molecular approach to identifying the prey of cephalopod paralarvae. ICES J. Mar. Sci. 2010, 67, 1408-1412. [CrossRef]

20. Roura, Á. Ecología de Paralarvas Planctónicas de Cefalópodos en Áreas de Afloramiento Costero. Ecology of Planktonic Cephalopod Paralarvae in Coastal Upwelling Systems. Ph.D. Thesis, Universidad de Vigo, Vigo, Spain, 2013; p. 219.

21. Lourenço, S.; Roura, Á.; Fernández-Reiriz, M.S.; Narciso, L.; González, A. Feeding relationship between Octopus vulgaris (Cuvier, 1797) early life-cycle stages and their prey in the western Iberian upwelling system: Correlation of reciprocal lipid and fatty acid contents. Front. Physiol. 2017. [CrossRef] [PubMed]

22. Boletzky, S.V.; Hanlon, R.T. A review of the laboratory maintenance, rearing and culture of cephalopod molluscs. Mem. Natl. Mus. Vic. 1983, 44, 147-187. [CrossRef]

23. Roura, Á.; González, Á.; Redd, K.; Guerra, Á. Molecular prey identification in wild Octopus vulgaris paralarvae. Mar. Biol. 2012, 159, 1335-1345. [CrossRef]

24. Mangold, K. Octopus vulgaris. In Cephalopod Life Cycles Vol. I: Species Acounts; Boyle, P.R., Ed.; Academic Press: London, UK, 1983; p. 475.

25. Otero, J.; Álvarez-Salgado, X.A.; González, A.F.; Gilcoto, M.; Guerra, A. High-frequency coastal upwelling events influence Octopus vulgaris larval dynamics on the NW Iberian shelf. Mar. Ecol.-Prog. Ser. 2009, 386, 123-132. [CrossRef]

26. Roura, Á.; Antón Álvarez-Salgado, X.; González, Á.F.; Gregori, M.; Rosón, G.; Otero, J.; Guerra, Á. Life strategies of cephalopod paralarvae in a coastal upwelling system (NW Iberian Peninsula): Insights from zooplankton community and spatio-temporal analyses. Fish. Oceanogr. 2016, 25, 241-258. [CrossRef]

27. Kiefer, D.; Strickland, J.D.H. A comparative study of photosynthesis in seawater samples incubated under two types of light attenuator. Limnol. Oceanogr. 1970, 15, 408-412. [CrossRef]

28. Almansa, E. (Spanish Institute of Oceanography, Santa Cruz de Tenerife, Spain). Personal communication, 2012.

29. Vidal, E.A.G.; Dimarco, F.P.; Wormuth, J.H.; Lee, P.G. Optimizing rearing conditions of hatchling loliginid squid. Mar. Biol. 2002, 140, 117-127.

30. Hulet, W.H.; Villoch, M.R.; Hixon, R.F.; Hanlon, R.T. Fin damage in capture and reared squids. Lab. Anim. Sci. 1979, 29, 528-533. [PubMed]

31. Sykes, A.V.; Quintana, D.; Andrade, J.P. The effects of light intensity on growth and survival of cuttlefish (Sepia officinalis, Linnaeus 1758) hatchlings and juveniles. Aquac. Res. 2014, 45, 2032-2040. [CrossRef]

32. Sykes, A.V.; Gonçalves, R.A.; Andrade, J.P. Early weaning of cuttlefish (Sepia officinalis, L.) with frozen grass shrimp (Palaemonetes varians) from the first day after hatching. Aquac. Res. 2013, 44, 1815-1823. [CrossRef] 
33. Shashar, N.; Hagan, R.; Boal, J.G.; Hanlon, R.T. Cuttlefish use polarization sensitivity in predation on silvery fish. Vis. Res. 2000, 40, 71-75. [CrossRef]

34. Nanton, D.A.; Castell, J.D. The effects of dietary fatty acids on the fatty acid composition of the harpacticoid copepod, Tisbe sp., for use as a live food for marine fish larvae. Aquaculture 1998, 163, 251-261. [CrossRef]

35. Støttrup, J.G. Production and Nutritional Value of Copepods. In Live Feeds in Marine Aquaculture; Støttrup, J.G., McEvoy, L., Eds.; Blackwell Science Ltd.: Bodmin, Cornwall, UK, 2007; pp. 145-205.

36. Repolho, T.; Baptista, M.; Pimentel, M.S.; Dionisio, G.; Trubenbach, K.; Lopes, V.M.; Lopes, A.R.; Calado, R.; Diniz, M.; Rosa, R. Developmental and physiological challenges of octopus (Octopus vulgaris) early life stages under ocean warming. J. Comp. Physiol. B Biochem. Syst. Environ. Physiol. 2014, 184, 55-64. [CrossRef] [PubMed]

37. Iglesias, J.; Fuentes, L.; Sánchez, J.; Otero, J.J.; Moxica, C.; Lago, M.J. First feeding of Octopus vulgaris Cuvier, 1797 paralarvae using Artemia: Effect of prey size, prey density and feeding frequency. Aquaculture 2006, 261, 817-822. [CrossRef]

38. Uriarte, I.; Hernández, J.; Dörner, J.; Paschke, K.; Farías, A.; Crovetto, E.; Rosas, C. Rearing and growth of the octopus Robsonella fontaniana (Cephalopoda: Octopodidae) from planktonic hatchlings to benthic juveniles. Biol. Bull. 2010, 218, 200-210. [CrossRef] [PubMed]

39. Franco-Santos, R.M.; Perales-Raya, C.; Almansa, E.; De Troch, M.; Garrido, D. Beak microstructure analysis as a tool to identify potential rearing stress for Octopus vulgaris paralarvae. Aquac. Res. 2016, 47, 3001-3015. [CrossRef]

40. Oh, Y.K.; Seol, E.; Kim, M.S.; Park, S. Photoproduction of hydrogen from acetate by a chemoheterotrophic bacterium Rhodopseudomonas palustris P4. Int. J. Hydrog. Energy 2004, 29, 1115-1121. [CrossRef]

41. Zar, J.H. Biostatistical Analysis, 4th ed.; Prentice-Hall Inc.: Upper Saddle River, NT, USA, 1999.

42. Fowler, J.; Cohen, L.; Jarvis, P. Practical Statistics for Field Biology; Wiley: New York, NY, USA, 1998; p. 256.

(C) 2017 by the authors. Licensee MDPI, Basel, Switzerland. This article is an open access article distributed under the terms and conditions of the Creative Commons Attribution (CC BY) license (http://creativecommons.org/licenses/by/4.0/). 